\title{
Preditores da síndrome de burnout em docentes do ensino privado
}

\author{
Patrícia Dalagasperina - Universidade do Vale do Rio dos Sinos, São Leopoldo, Brasil \\ Janine Kieling Monteiro - Universidade do Vale do Rio dos Sinos, São Leopoldo, Brasil
}

\begin{abstract}
Resumo
A profissão docente representa uma das categorias mais acometidas pela síndrome de burnout. Com intuito de identificar os fatores de estresse laboral e as variáveis sóciodemográficas preditoras desta doença, foram investigados 202 professores do ensino privado no Rio Grande do Sul - Brasil. Para o levantamento dos dados, utilizou-se o Questionário para Avaliação da síndrome de burnout, um Questionário Sociodemográfico e Laboral e uma Escala sobre Fatores de Estresse no Trabalho, ambos elaborados pelas autoras a partir da revisão da literatura. Foram realizadas análises descritivas e de regressão linear múltipla. Os resultados indicaram um modelo explicativo para cada dimensão da síndrome de burnout. A maioria dos fatores preditivos refere-se à organização do trabalho, ressaltando-se as dificuldades em relação aos alunos. Os achados deste estudo podem subsidiar programas preventivos do adoecimento mental no trabalho docente.
\end{abstract}

Palavras-Chave: Síndrome de burnout; Docentes; Fatores preditores; Ensino privado; Estresse.

\section{Predictors of burnout syndrome for teachers in private education}

\begin{abstract}
The teaching jobs are one of the most affected groups by burnout syndrome. With the intention of identifying factors of workstress and sociodemographic variables predictive of this disease, 202 teachers from private schools in Rio Grande do Sul - Brasil were investigated. To gather the data we have used the Questionnaire for Assessing burnout syndrome, a Socio Demographic and Labour Questionnaire and a Scale about Stressors at Work, both developed by the authors from the literature review. Descriptive and multiple linear regression analysis of the data were performed. The results indicated an explanatory model for each dimension of the burnout syndrome. Most predictors are related to the organization of work highlighting the difficulties in relation to students. The findings of this study can promote mental disease prevention programs in the teaching jobs.
\end{abstract}

Keywords: Burnout syndrome; Teachers; Predictors; Private education; Stress.

\section{Predictores del síndrome de burnout en docentes de la enseñanza privada}

\begin{abstract}
Resumen
La docencia es una de las ocupaciones más afectadas por el síndrome de burnout. Con el objetivo de identificar los factores de estrés laboral y las variables sociodemográficas que predicen la enfermedad, fueron investigados 202 docentes de escuelas privadas de Rio Grande do Sul - Brasil. Para recolectar los datos se utilizó el Cuestionario para la Evaluación del Síndrome de Burnout, un Cuestionario Sociodemográfico y Laboral, y una Escala sobre Factores de Estrés en el Trabajo, ambos elaborados por las autoras a partir de la revisión bibliográfica. Se realizaron análisis descriptivos y de regresión lineal múltiple. Los resultados indicaron un modelo explicativo para cada dimensión del síndrome de burnout. La mayoría de los predictores se refiere a la organización del trabajo, destacando las dificultades en relación a los estudiantes. Los resultados de este estudio pueden servir como base para programas de prevención de enfermedades mentales en el trabajo docente.

Palabras-clave: Síndrome de burnout; Docentes; Factores predictores; Enseñanza privada; Estrés.
\end{abstract}

\section{Introdução}

O trabalho docente está cercado por diversos fatores de estresse. Os conteúdos curriculares da formação dos professores dissociados da demanda (Lima, Barreto \& Lima, 2007), a ausência de capacitação para lidar com as exigências do trabalho (Ferreira \& Assmar, 2008; Xavier, 1978), a necessidade de manter a disciplina entre os alunos, a sobrecarga extraclasse, bem como as dificuldades nas relações interpessoais, são fatores que contribuem para o estresse ocupacional (Lipp, 2002/2007). O excesso de atividades e o desgaste emocional a que os docentes estão sujeitos no trabalho tornam-os mais susceptíveis e vulneráveis ao desenvolvimento de transtornos relacionados ao estresse (Andrade \& Cardoso, 2012; Assmar \& Ferreira, 2008; Escalona, Sánchez \& Medina, 2007; Figueiredo, Pereira \& Brás, 2007).

Os professores preparam e ministram aulas, corrigem provas e trabalhos e precisam manter-se constantemente atualizados nos conteúdos que transmitem. Além destas tarefas rotineiras, também se ocupam da gestão escolar, que inclui atividades de planejamento, elaboração de projetos, avaliação de currículos, serviços administrativos, orientação de alunos, atendimento aos pais, envolvimento na elaboração de atividades 
extraescolares e participação de reuniões e assembleias (Carlotto, 2010a; Oliveira, 2003).

Embora o desempenho de todas estas tarefas se configure, por si só, como um fator de desgaste e estresse (Correa, Zambrano \& Chaparro, 2010; Marqueze \& Moreno, 2009; Silvério, Patrício, Bordbeck \& Grosseman, 2010), os professores ainda necessitam conviver com a desvalorização de seu trabalho. Isso pode ser evidenciado pelo fato de que o professor não possui um reconhecimento financeiro condizente com a sua atividade, o que é representado pelos salários insatisfatórios que recebe (Donatelli \& Oliveira, 2010; Lipp, 2002, 2007; Noronha, Assunção \& Oliveira 2008; Odelius \& Codo, 1999). Outra questão a ser destacada é que os docentes sofrem com situações de desrespeito provenientes da indisciplina de alguns alunos (Gomes, Silva, \& Silva, 2010; Gomes, Montenegro, Peixoto \& Peixoto, 2010; Ramos \& Machado, 2010; Rosso, 2011). A tensão derivada das condições adversas de trabalho pode desenvolver sintomas que vão desde as fases iniciais do estresse até a instalação da síndrome de burnout (SB) (Rocha \& Fernandes, 2008; Servilha \& Arbach, 2011).

A profissão docente é uma das categorias mais acometidas pela SB (Codo \& Vasquez-Menezes, 1999). Descrita por Maslach e Jackson (1986, citado por Tamayo \& Troccóli, 2002) a síndrome de burnout se refere a uma experiência individual negativa, que decorre das relações interpessoais no ambiente de trabalho e tem como alvo os profissionais dos serviços humanos, como: médicos, professores, policiais. Composta, inicialmente, por três dimensões, a SB foi explicada pela exaustão emocional, pela despersonalização e pela diminuição da realização pessoal no trabalho (Tamayo \& Tróccoli, 2002).

No ano de 2005, Gil-Monte ampliou esta concepção inicial ao descrever um novo modelo de SB composto por quatro dimensões. A primeira refere-se à ilusão pelo trabalho, que considera o desejo individual para o alcance das metas profissionais; a segunda dimensão está relacionada ao desgaste psíquico, caracterizado por sentimentos de exaustão física e emocional, pelo contato direto com as pessoas responsáveis pela fonte dos problemas. A indolência, terceira dimensão, consiste na presença de atitudes de indiferença junto aos usuários do serviço prestado e na ausência de sensibilidade aos problemas alheios. Na última dimensão, $\mathrm{o}$ autor sugere que o sujeito vivencia um sentimento de culpa, e de cobrança acerca do comportamento e das atitudes negativas desenvolvidas no trabalho, que é evidenciada, principalmente, em sujeitos que desenvolvem relações diretas no ambiente de trabalho (Gil-Monte, 2005).

As investigações acerca da síndrome de burnout em professores têm sido realizadas tanto em docentes cujas áreas de ensino variam (Machado, Porto-Martins \& Amorim, 2012; Moreira, Farias, Bhot \& Nascimento, 2009; Schwarzer \& Hallum, 2008) quanto em estudos que dividem a amostra de acordo com o nível de ensino que lecionam (Carlotto, 2010b; Monteiro, Dalagasperina \& Quadros, 2012; Moreira e cols., 2009; Santos \& Sobrinho, 2011). Apesar de apontar diferenças nos índices de burnout, os estudos revelam a presença da Síndrome em todos os níveis de ensino, sendo, portanto, uma questão que abrange toda a categoria profissional.

A literatura exibe alguns estudos de revisão sobre a síndrome de burnout. $\mathrm{Na}$ investigação realizada por Trigo, Teng, e Hallak (2007), dentre os anos de 1985 a 2006, identificou-se que os efeitos dessa patologia podem prejudicar o profissional tanto em nível individual, profissional quanto organizacional. A revisão sistemática da síndrome de burnout em professores, realizada no período de 1989 a 2009, indica uma elevada prevalência da doença entre os profissionais do ensino fundamental e médio e revela que ela está associada às características do trabalho docente, em detrimento da carga horária em sala de aula e do número de alunos por turma (Santos \& Sobrinho, 2011).No mesmo sentido, uma revisão bibliográfica de estudos qualitativos, fez uma reflexão acerca dos principais fatores de risco para o desenvolvimento da síndrome de burnout entre professores. A investigação revelou a escassez de estudos descritivos na área e apontou a necessidade de pesquisas que possam clarificar a compreensão sobre a insatisfação profissional, o baixo rendimento no trabalho, o absenteísmo e algumas doenças ocupacionais (Andrade \& Cardoso, 2012). No Brasil, a produção científica sobre a SB aponta que os professores e os trabalhadores da saúde são as categorias profissionais mais pesquisadas (Carlotto \& Câmara, 2008).

Um estudo realizado com 258 professores mexicanos revelou que os participantes que possuem maior dedicação ao ensino manifestaram os níveis mais altos de estresse e burnout, e que os professores com contrato integral apresentaram maior estresse do que os profissionais que atuavam meio período ou daqueles que eram contratados por horas (Galicia \& Zermeño, 2009). Em relação à competência pessoal no trabalho, uma pesquisa realizada na Espanha, com 193 
professores universitários, concluiu que fatores relacionados às condições laborais, como a sobrecarga e a ambiguidade, podem enfraquecer os sentimentos de competência pessoal. Além disso, a percepção dessa competência influencia, negativamente, o nível de despersonalização e, positivamente, os sentimentos de realização profissional, enquanto a sobrecarga de trabalho aumenta o nível de exaustão profissional (Navarro, Mas \& Jiménez, 2010). No Chile, uma pesquisa com objetivo de analisar a relação entre as dimensões da síndrome de burnout, apoio social e satisfação no trabalho, investigou 89 professores de estabelecimentos municipais de ensino. Os resultados revelam que os professores apresentavam sintomatologia significativa e presença de síndrome de burnout. No entanto, as variáveis de apoio social e de satisfação no trabalho relacionam-se de forma inversa com as dimensões do burnout, indicando que as mesmas auxiliam na redução dos níveis dessa doença (Jiménez, Figueroa, Gutiérrez \& Celis, 2012).

No que se refere à prevalência de burnout, uma pesquisa mexicana com 698 docentes indicou escores altos na exaustão psicológica nos participantes, no entanto, os níveis relacionados à falta de entusiasmo pelo trabalho foram baixos, sugerindo que apesar de apresentar indicativos de estresse, esse grupo sentese realizado em relação à docência (Rojas, Ocaña \& Gil-Monte, 2008). Já, no Brasil, um estudo com 265 professores apresentou um percentual mais elevado na dimensão da baixa realização profissional e um menor percentual na despersonalização. $\mathrm{O}$ estudo apontou ainda que quanto mais elevada a carga horária maior foi o desgaste emocional e menor foi a realização com o trabalho. E quanto maior foi o número de alunos atendidos por dia, maior foi o desgaste emocional e a despersonalização e mais baixa foi a realização profissional (Carlotto, 2011).

Com intuito de investigar possíveis associações entre as dimensões da $\mathrm{SB}$ e as variáveis demográficas, laborais e psicossociais, um estudo investigou 34 professores que atuam na educação infantil em Porto Alegre. Os resultados apontaram baixos índices nas dimensões de exaustão emocional e despersonalização e alto índice de realização profissional. Em relação às variáveis demográficas, a variável ter companheiro relacionou-se a exaustão emocional, apontando média mais elevada nessa dimensão. Resultados relacionados às variáveis laborais e psicossociais revelam que quanto maior a carga horária, o número de alunos atendidos diariamente, o tempo de docência e o pensamento de mudar de profissão, maior é a exaustão emocional (Rodrigues, Chaves \& Carlotto, 2010). Dados similares são encontrados em um estudo sobre estresse e burnout realizado com 333 professores do ensino superior. Os resultados indicaram níveis acentuados de estresse ocupacional e de burnout, principalmente, em relação à exaustão emocional. Além disso, os professores que avaliaram a profissão de forma mais negativa apresentaram maiores níveis de estresse e burnout (Gomes, Oliveira, Esteve, \& Alvelos, 2013).

Apesar das publicações nacionais e internacionais destacarem a síndrome de burnout em professores como uma preocupante forma de adoecimento no trabalho, a questão parece estar longe de ser solucionada. Arís (2009) refere, em seu estudo, que esta patologia ocupacional se apresenta como um problema crescente para os professores. Diante deste contexto, o presente estudo propõe-se a analisar os fatores de estresse laboral e as variáveis sociodemográficas preditoras das dimensões da síndrome de burnout em professores do ensino privado no estado do Rio Grande do Sul - Brasil.

\section{Método}

\section{Delineamento}

Para atingir os objetivos propostos pelo estudo, utilizou-se o método quantitativo de caráter correlacional e explicativo. Para isso foi realizada a análise de regressão linear múltipla, que visa descobrir modelos de como diversas variáveis se relacionam a uma variável dependente (Dancey \& Reydi, 2006, 2008).

\section{Amostra}

O Rio Grande do Sul conta com aproximadamente 35.000 professores na rede particular de ensino. Por meio de um cálculo amostral (Santos s/a) com índice de confiança de $95 \%$ e taxa de erro $5 \%$, previu-se o número de 380 participantes. Dos 426 professores que se disponibilizaram a participar deste estudo, 202 retornaram os questionários, o que representa um taxa de resposta de 47,9\%. Embora o estudo não tenha atingido este número, considera-se que uma amostra de 200 participantes pode ser adequada para detectar pequenos a médios effect sizes.

O grupo investigado foi composto por 202 professores, que atuam em diferentes níveis de ensino: infantil (10,4\%), fundamental (31,7\%), médio $(24,8 \%)$ e superior $(33,2 \%)$ da rede privada do Rio Grande do Sul. Estes exercem suas atividades em Porto Alegre (31,2\%), na Região Metropolitana de Porto Alegre (29,2\%) e em 
outras quatro cidades do interior do estado: Santa Maria $(12,4 \%)$, Passo Fundo (10,4\%), Caxias do Sul $(9,4 \%)$ e Pelotas. $(6,9 \%)$. A escolha por cidades participantes se deu em função de serem os centros urbanos que concentram o maior número de professores no ensino privado nesse estado, segundo dados fornecidos pelo Sindicato dos Professores do Ensino Privado do Rio Grande do Sul (SINPRO-RS).

A maior parte da amostra foi formada por: mulheres $(64,9 \%)$, com relação estável (67\%), nível superior completo $(41,3 \%)$, que leciona no ensino superior $(32,7 \%)$. Verificou-se, também, que a maior parte dos profissionais possui carga horária de 20 a 40 horas semanais $(36 \%)$, desenvolve as suas atividades em uma instituição $(52 \%)$ e não possui outra atividade remunerada, além da docência (71,4\%).

Em relação às varáveis intervalares, a idade dos participantes variou entre 25 e 70 anos $(M=42,7$; $D P=10,3)$, o tempo de formação esteve entre um e 47 anos $(M=18,3 ; D P=10,5)$. Já o tempo de experiência na profissão e o tempo de experiência no local de trabalho se apresentaram, respectivamente, entre um e 47 anos $(M=18,4 ; D P=10,5)$ e entre um mês e 40 anos $(M=11,3$; $D P=9,11)$. Como critério de inclusão neste estudo foi considerado que os participantes deveriam ter experiência de, no mínimo, um ano na profissão.

\section{Instrumentos}

Para o levantamento dos dados utilizaram-se três instrumentos: um questionário para a avaliação da síndrome de burnout, um questionário de dados sociodemográficos e laborais e uma escala de estresse no trabalho docente.

Para avaliar as dimensões da síndrome de burnout, foi utilizado o Cuestionario para la Evaluación del Sindrome de Quemarse por el Trabajo /CESQ, de Gil-Monte (2005), validado para o Brasil por Gil-Monte, Carlotto e Câmara (2010). O instrumento consta de 20 itens, que se distribuem em quatro subescalas, denominadas: ilusão para o trabalho ( 5 itens, alfa $=0,72$ ); desgaste psíquico ( 4 itens, alfa $=0,86)$, indolência ( 6 itens, alfa $=0,75)$ e, culpa ( 5 itens, alfa $=0,79)$. Os itens são avaliados com uma escala tipo likert de frequência de cinco pontos (0 "nunca" a 4 "todos os dias"). Obtiveram-se, nesta pesquisa os seguintes índices de consistência interna nas subescalas: ilusão para o trabalho (alfa $=0,88)$; desgaste psíquico $(\mathrm{alfa}=0,85)$; indolência $(\mathrm{alfa}=0,79)$; e, culpa $(\mathrm{alfa}=0,81)$.

A partir da revisão da literatura, foram elaborados um questionário sociodemográfico e laboral e uma Escala de Estresse no Trabalho docente. O questionário buscou levantar característica tais como: sexo, idade, tempo de experiência na profissão. Já na escala de estresse foram avaliados 25 itens, por meio de uma escala tipo likert de cinco pontos (que variava de 1- nunca, 2- raramente, 3- às vezes, 4- frequentemente e 5- sempre). Os itens descreviam fatores de estresse presentes no trabalho dos professores, relacionados às atividades realizadas,à falta de reconhecimento, à baixa remuneração e às dificuldades de relacionamento com alunos, chefias e colegas. Apesar da escala ainda não ter sido validada, obteve-se neste estudo um alfa de 0,90 na escala total.

\section{Procedimentos éticos}

O presente estudo foi aprovado pelo Comitê de Ética em Pesquisa da Universidade X sob o número CEP 11/134 e atendeu às exigências éticas previstas na Resolução 196/96 do Conselho Nacional de Saúde (Brasil, 1996) e na Resolução 016/2000 do Conselho Federal de Psicologia (Brasil, 2000). Mediante da assinatura do Termo de Consentimento Livre e Esclarecido (TCLE), os participantes autorizaram a utilização dos dados para fins de pesquisa e foram informados dos objetivos do estudo. Tomaram conhecimento de que a contribuição seria realizada de forma voluntária e que poderiam desistir em qualquer momento do processo, sem que isso lhes causasse prejuízo.

Os dados foram registrados e serão armazenados pelo período de cinco anos, conforme a exigência legislativa. A devolução foi realizada mediante envio de um e-mail, no qual consta o agradecimento pela participação no estudo e um link (http://www.feteesul.or.br/pdf/ professoresnolimite.pdf) para acessar uma publicação que relata os principais resultados da pesquisa.

\section{Procedimento de coleta de dados}

A coleta de dados foi realizada via Correio. Após a definição das cidades, realizaram-se dois sorteios para ter acesso à amostra: primeiramente sortearam-se as instituições dentre as cidades participantes; logo após foram sorteados os professores que trabalham nessas instituições. $\mathrm{O}$ acesso às listas de escolas, bem como às listas de professores, com seus respectivos contatos, deu-se por intermédio do Sindicato dos Professores do Ensino Privado do Rio Grande do Sul (SINPRO-RS).

Os participantes receberam em seu endereço os instrumentos da pesquisa, as duas vias do TCLE, uma lista de instruções para preencher os instrumentos e um envelope selado e pago para retorno do material. $\mathrm{O}$ 
convite para participar da pesquisa foi realizado, inicialmente, por e-mail. Nos casos em que o e-mail retornou e naqueles em que não houve resposta dentro de 15 dias o convite foi reforçado por contato telefônico. $\mathrm{O}$ período de realização da coleta ocorreu entre os meses de outubro de 2011 e de janeiro de 2012.

\section{Procedimento de análise de dados}

Os resultados das escalas e do questionário foram levantados e tabulados em banco de dados. A análise descritiva dos instrumentos envolveu frequência, medidas de tendência central, dispersão e propriedades da distribuição para as variáveis de interesse. Para analisar os fatores preditores da síndrome de burnout utilizou-se a Análise de Regressão Linear Múltipla, modelo Stepwise, tendo as dimensões da SB como variáveis dependentes e as características sociodemográficas e laborais e os itens da Escala de Estresse no Trabalho Docente como variáveis independentes. Todas as análises foram conduzidas no programa SPSS for Windows (versão 19.0).

\section{Resultados}

Por meio da análise de regressão linear múltipla, pode-se observar um modelo preditor das dimensões da síndrome de burnout. O grupo responsável por explicar 21,6\% da variância da ilusão pelo trabalho foi composto por três variáveis: falta de capacitação para resolver questões relacionadas ao trabalho, falta de reconhecimento do trabalho por parte da sociedade e a falta de educação e limite dos alunos. Cabe destacar que a falta de capacitação apresenta maior poder explicativo, representando $17 \%$ da variância (Tabela 1). Além disso, ressalta-se que esta dimensão é avaliada de forma positiva no instrumento, por isso os fatores associados a esta no modelo explicativo apresentam uma direção negativa, o que contribui para a redução nos níveis da ilusão pelo trabalho.

Em relação à dimensão desgaste psíquico, o conjunto de variáveis explicativas que representa $55,5 \%$ da variância é formado pela: sobrecarga de trabalho extraclasse; falta de reconhecimento do trabalho por parte

Tabela 1. Regressões lineares múltiplas

\begin{tabular}{lccccc}
\hline Variáveis dependentes & $\mathrm{R}$ & $\begin{array}{c}\mathrm{R}^{2} \\
\text { Adjusted }\end{array}$ & Beta & $\mathrm{T}$ & $\mathrm{P}$ \\
Variáveis independentes & & & & & \\
\hline Ilusão pelo trabalho & 0,424 & 0,170 & $-0,254$ & $-3,511$ & 0,001 \\
1. Falta de capacitação para o trabalho & 0,462 & 0,199 & $-0,252$ & $-3,412$ & 0,001 \\
2. Falta de reconhecimento/ sociedade & 0,185 & 0,216 & $-0,175$ & $-2,325$ & 0,021 \\
3. Falta de limite e educação/ alunos & & & & & \\
\hline Desgaste Psíquico & 0,565 & 0,312 & 0,274 & 3,833 & 0,000 \\
1. Sobrecarga de trabalho extraclasse & 0,698 & 0,471 & 0,250 & 3,679 & 0,000 \\
2. Falta de reconhecimento/ alunos & 0,726 & 0,508 & 0,193 & 3,157 & 0,002 \\
3. Medo de demissão & 0,747 & 0,535 & 0,196 & 2,758 & 0,006 \\
4. Tarefas que estão além da sua função & 0,762 & 0,555 & 0,136 & 2,133 & 0,034 \\
5. Falta de educação e de limite/ alunos & & & & & \\
\hline Indolência & 0,517 & 0,263 & 0,274 & 3,833 & 0,000 \\
1. Falta de reconhecimento/ alunos & 0,591 & 0,342 & 0,250 & 3,679 & 0,000 \\
2. Dificuldade de relacionamento/ alunos & 0,610 & 0,361 & 0,193 & 3,157 & 0,002 \\
3. Sexo & 0,635 & 0,389 & 0,196 & 2,758 & 0,006 \\
4. Falta de educação e de limite/alunos & 0,674 & 0,401 & 0,136 & 2,133 & 0,034 \\
5. Conflito entre valores / tarefas a realizar & & & & & \\
\hline Culpa & 0,403 & 0,154 & 0,288 & 2,893 & 0,005 \\
1. Conflito entre valores/ tarefas a realizar & 0,450 & 0,186 & 0,301 & 2,851 & 0,005 \\
2. Tarefas que estão além da sua função & 0,486 & 0,213 & $-0,197$ & $-2,099$ & 0,038 \\
3. Baixa remuneração & & & &
\end{tabular}


dos alunos, falta de educação e limite dos alunos, medo de demissão e executar tarefas que estão além da sua função. Nesse grupo a variável que possui maior poder para explicar a dimensão foi à sobrecarga de trabalho extraclasse, com 31,2\% de variância (Tabela 1).

A indolência apresentou 40,1\% de variância e foi explicada pelas seguintes variáveis: falta de reconhecimento do trabalho pelos alunos, que possui maior poder explicativo, com $26,3 \%$ de variância; dificuldades de relacionamento com os alunos, sexo, falta de educação e limite dos alunos e conflito entre os valores pessoais e as tarefas que devem desenvolver. Por fim, a dimensão culpa, que representa $21,3 \%$ da variância, foi explicada por três variáveis, sendo duas positivas: conflito entre os valores pessoais e as tarefas que devem desenvolver $(15,4 \%)$ e pelas tarefas que estão além da sua função. De forma negativa, a dimensão foi explicada pela baixa remuneração.

\section{Discussão}

A análise estatística constatou a predominância dos fatores de estresse laboral nos modelos explicativos das quatro dimensões da síndrome burnout. Resultados semelhantes também foram encontrados em outros estudos (Maslach \& Leiter, 1997; Carlotto \& Câmara, 2007). Dentre o conjunto das variáveis preditoras, apenas a dimensão indolência foi explicada também, pela variável sociodemográfica: sexo masculino. Esse resultado se aproxima do entendimento da síndrome de burnout como um problema do meio social, onde o indivíduo exerce suas atividades laborais, e não de problemas de ordem pessoal (Maslach \& Leiter, 1999).

A falta de capacitação para lidar com as questões do trabalho, a falta de reconhecimento do trabalho (por parte da sociedade) e a falta de limite e de educação dos alunos formam o modelo explicativo da ilusão pelo trabalho, o que ressalta a importância do desejo individual para o alcance das metas profissionais. Nota-se que as variáveis preditoras dessa dimensão relacionam-se a uma carência de reconhecimento do trabalho e de recursos para desempenhá-lo. $\mathrm{Na}$ medida em que o professor se depara com suas limitações para desenvolver as atividades laborais, ocorre uma redução do seu sentimento de competência, fundamental para autoestima e para a realização no trabalho. A sensação de incompetência, proveniente dessa dificuldade, ganha força ao se deparar com a desvalorização do trabalho pela sociedade e ao conviver com o desrespeito por parte dos alunos.
A variável mais explicativa da dimensão ilusão pelo trabalho foi a falta de capacitação para lidar com as questões ocupacionais. Esta pode estar relacionada a uma lacuna proveniente da formação dos professores. As transformações neste processo devem se realizar através de um sistema de formação continuada, que priorize métodos de intervenção condizentes com as demandas reais dos alunos e da sociedade (Lima e cols., 2007). Nesse sentido, a frequente insuficiência de recursos didáticos surge como um dos fatores que leva o profissional ao desgaste emocional e pode estar associada à sua realização com o trabalho (Lipp 2002, 2007; Moreira e cols., 2009). Além disso, a necessidade constante de atualizações provenientes do avanço das transformações tecnológicas, associadas à sobrecarga laboral docente, dificulta a qualificação dos professores, uma vez que não há tempo para dar conta de todas estas exigências (Ferreira \& Assmar, 2008; Xavier, 1978).

A relação entre o mau comportamento dos alunos, e a ilusão pelo trabalho também foi encontrada no estudo de Carlotto e Palazzo (2006). Entende-se, a partir dessa associação, que as dificuldades com os alunos diminuem a realização com o trabalho. Resultados de um estudo sobre o estresse ocupacional docente apontam que dentre as dez áreas de tensão mais comuns no trabalho, consideradas pelos professores, oito dizem respeito ao comportamento inadequado dos alunos (Gomes, e cols., 2010).

$\mathrm{Na}$ dimensão desgaste psíquico, o grupo de variáveis preditoras relaciona-se ao excesso de atividades (sobrecarga de trabalho e execução de tarefas que estão além da função), a um descontentamento com os alunos (falta de reconhecimento e mau comportamento) e à insegurança diante da possibilidade da perda do emprego (medo de ser demitido). Cabe destacar que a sobrecarga de trabalho, preditor que mais explicou essa dimensão, tem sido apontada como um dos principais fatores de estresse na profissão docente (Correa e cols., 2010; Marqueze \& Moreno, 2009; Silvério e cols., 2010). O excesso de atividades laborais está diretamente relacionado ao desgaste e pode ser percebido pela redução da capacidade física e/ou mental (Escalona e cols., 2007). Além disso, evidenciou-se, neste estudo, a realização de tarefas que estão além da sua função docente, tais como: organizar viagens, varrer salas de aula, organizar eventos em datas comemorativas. As tarefas desnecessárias e não relacionadas à essência da profissão fazem com que os professores sintam-se desrespeitados em seu trabalho (Carlotto, 2010a). 
O sentimento de insegurança diante de uma possível demissão também apresentou correlação com a exaustão emocional, em um estudo realizado com professores de educação física no Rio Grande do Sul (Moreira e cols., 2009). Tal instabilidade parece ser uma particularidade do ensino privado. Os professores da rede particular vivenciam de forma constante o medo de perder o emprego, especialmente nas situações de contenção de gastos, de crises financeiras e no término do ano letivo, quando surge o receio de que um professor possa entrar no período de estabilidade (Donatelli \& Oliveira, 2010).

O grupo de variáveis preditoras da dimensão indolência é formado, em sua maioria, por fatores de estresse relacionados aos alunos: falta de reconhecimento, dificuldades de relacionamento e falta de limite e educação. A dimensão é explicada também, pelo sexo e pelo conflito decorrente dos valores pessoais e das tarefas realizadas no trabalho.

A indolência caracteriza-se pelo sentimento de indiferença relacionado às pessoas atendidas. Desse modo, a ausência de reconhecimento do trabalho por parte dos alunos parece induzir ao distanciamento afetivo dos professores. A falta de reconhecimento proveniente do desinteresse e da indisciplina dos alunos, bem como das salas de aula lotadas, se configuram como os principais fatores de desgaste no trabalho docente (Rosso, 2011).

O sexo masculino, neste estudo, apresenta-se associado a maior indolência. Esse resultado parece confirmar outras investigações que o identificam como preditor dessa dimensão (Carlotto, 2011; Rojas, 2010). Pensa-se, a partir disto, que o papel social do homem se configura de forma mais racional e menos emotiva em comparação às mulheres, o que pode lhes permitir o distanciamento afetivo dos alunos. Já o sexo feminino apresenta maior envolvimento com questões de cuidado, preocupação e bem estar do outro (Carlotto, 2010a).

O conflito entre os valores pessoais e as atividades realizadas, a execução de tarefas que estão além da função e a baixa remuneração são as variáveis preditoras da culpa. Essa dimensão caracteriza-se por sentimentos de cobrança ante os comportamentos laborais negativos.

A variável com maior poder explicativo foi a necessidade de priorizar valores organizacionais contrários aos valores de ordem pessoal, o que dá origem a um conflito ético. Quanto mais distantes estiverem os valores pessoais dos valores organizacionais, maior será a probabilidade da emergência de conflitos (Schwarzer \& Hallum, 2008).

A baixa remuneração, que apareceu como um fator preditivo da culpa, tem sido mencionada na literatura como um estressor ocupacional da profissão docente. (Lipp, 2002, 2007; Noronha e cols., 2008; Odelius \& Codo, 1999). Contudo, neste estudo, a relação negativa entre a dimensão e a baixa remuneração pode ser entendida do ponto de vista de que o professor julga não merecer a compensação financeira que recebe. Tal sentimento pode estar associado à sua percepção negativa sobre o comportamento que desempenha no trabalho. A sensação de estar sendo super-recompensado é vivenciada como injusta e acompanhada por sentimentos de raiva e culpa, que podem culminar em um esgotamento profissional (Assmar \& Ferreira, 2008).

Diante desses resultados, que indicaram vários fatores estressores que contribuem para o desenvolvimento da síndrome de burnout em professores do ensino privado, urge a necessidade de planejamento de algumas intervenções que possam auxiliar na prevenção e redução desse adoecimento no grupo em foco. Nesse sentido, Monteiro e cols. (2012) referem que as intervenções em saúde mental no trabalho do professor podem englobar os níveis individual, grupal e organizacional e que o mais indicado seriam tomar medidas que envolvam conjuntamente esses níveis. Já Jiménez e cols. (2012) destacaram, como resultado de seu estudo, que o apoio social pode ser um fator que auxilia na redução dos níveis dessa doença.

Neste estudo sobressaíram-se, como problemáticas, questões relacionadas ao excesso de atividades e a dificuldades na relação com os alunos. A partir disso, sugerem-se algumas alternativas para essas questões. Indica-se a necessidade de revisar a quantidade de tarefas (tanto burocráticas como operacionais) realizadas pelos professores, visando desonerar o seu trabalho. No mesmo sentido poderia haver maior apoio do setor administrativo nas instituições privadas e menor número de alunos por turma. $\mathrm{Na}$ relação com os alunos, recomenda-se a realização de encontros com a comunidade (pais e alunos), instituições de ensino e professores para discutir temas que possam auxiliar na relação professor-aluno, tais como: educação, respeito e cidadania.

\section{Considerações finais}

Este estudo reforça a constatação de que a maior parte dos fatores preditores de burnout dizem respeito 
ao estresse relacionado à organização do trabalho. Identifica, ainda, o sexo masculino associado à dimensão indolência como um risco para o desenvolvimento da síndrome de burnout. Cabe destacar, novamente, que algumas dificuldades em relação aos alunos (falta de reconhecimento, falta de limite e de educação, dificuldades de relacionamento) compõem a maioria das variáveis preditoras e apresentam-se em três modelos explicativos, dentre as quatro dimensões que compõe esta doença ocupacional.

O conhecimento acerca dos fatores preditores da síndrome de burnout facilita a elaboração de medidas e programas de prevenção. Ressalta-se que este estudo apresenta limitações no que se refere ao número de participantes, uma vez que a amostra não foi atingida em razão do curto espaço de tempo para a coleta dos dados. Cabe destacar, ainda, que a amostra foi bastante diversificada no que diz respeito ao nível de ensino, o que, por um lado, pode ser um fator positivo, pois houve a representação de todos os grupos, mas, por outro lado, existem especificidades de cada nível que não puderam ser contempladas na análise realizada, o que limita a generalização dos dados para a categoria profissional. Ressalta-se, ainda, que este trabalho não esgota as possibilidades de investigação sobre o tema e sugere que novas pesquisas sejam realizadas.

A utilização de outros métodos de estudo, bem como a investigação das especificidades dentre as áreas do conhecimento, podem ampliar e facilitar o entendimento das variáveis explicativas das dimensões do burnout em professores. Sugerem-se, ainda, estudos com profissionais que apresentam este quadro patológico ou que já tenham tido há mais tempo, a fim de compreender as três etapas do processo: antes da instalação da patologia, durante a manifestação da doença e após a sua recuperação. Indica-se, também, que sejam realizadas pesquisas que possam analisar os preditores da SB de acordo com o nível de ensino em que os professores atuam.

Observa-se que a organização do trabalho docente se constitui como um fator de risco para o desencadeamento da síndrome de burnout. Portanto, torna-se necessário rever as políticas educativas, as formas de gestão e os métodos de intervenção utilizados nas instituições de ensino visando auxiliar o educador na sua árdua tarefa. Urge a necessidade de voltar a atenção a esses profissionais, que desempenham um papel relevante na sociedade.

\section{Referências}

Andrade, P. S., \& Cardoso, T. A. de O. (2012). Prazer e dor na docência: revisão bibliográfica sobre a síndrome de burnout. Saúde e Sociedade, 21(1), 129-140.

Arís, N. (2009). Burnout syndrome in educators. Electronic Journal of Research in Educational Psychology, 7(2), 829-848. Disponível em http:// convivencia.educa. aragon.es/admin/admin_1/file/Materiales $\% 20$ -Trab_investigaciones/Art_18_303.pdf.

Assmar, E. M. L., \& Ferreira, M. C. (2008). Da injustiça organizacional ao estresse e ao esgotamento profissional. Em A. Tamayo. (Org.), Estresse e cultura organizacional. (pp. 282-331). São Paulo: Casa do Psicólogo.

Brasil. Conselho Nacional de Saúde. Resolução no 196 de 10 de outubro de 1996. Diário Oficial da República Federativa do Brasil. Brasil (DF) 10 de outubro de 1996.

Brasil. Conselho Federal de Psicologia. Resolução $n^{0}$ 016/2000 de 20 de dezembro de 2000. Dispõe sobre a realização de pesquisa em psicologia com seres humanos. Diário Oficial da República Federativa do Brasil. Brasil (DF) 20 de dezembro de 2000.

Carlotto, M. S. (2010a). Sindrome de burnout: o estresse ocupacional do professor. Canoas: ULBRA.

Carlotto, M. S. (2010b). Síndrome de burnout: diferenças segundo níveis de ensino. Revista Psico, 41(4), 495-502.

Carlotto, M. S. (2011). Síndrome de burnout em professores: prevalência e fatores associados. Psicologia: Teoria e Pesquisa, 27(4), 403-410.

Carlotto, M. S., \& Palazzo, L. S. (2006). Síndrome de burnout e fatores associados: um estudo epidemiológico com professores. Cadernos de Saúde Pública, 22(5), 1017-1026.

Carlotto, M. S., \& Câmara, S. G. (2007). Preditores da síndrome de burnout em professores. Psicologia Escolar e Educacional, 11(1), 101-110.

Carlotto, M. S., \& Câmara, S. G. (2008). Análise de produção científica de burnout no Brasil. Revista Psico, 39(2), 152-158.

Codo, W., \& Vasques-Menezes, I. (1999). O que é Burnout? Em W. Codo (coord.), Educação: carinho e trabalbo. (pp. 237-254). Rio de Janeiro: Vozes. 
Correa, Z. C., Zambrano, I. M., \& Chaparro, A. F. (2010). Síndrome de burnout en docentes de universidades de Popayán, Colômbia. Revista de Salud Pública, 12(4), 589-598.

Dancey, C. P., \& Reidy, J. (Orgs.). (2008). Estatística sem matemática para psicologia: usando SPSS para windows. (L. Viali, trad.). Porto Alegre: Artmed. (Original publicado em 2006).

Donatelli, S., \& Oliveira, J. A. de (2010). O Trabalho de professores da educação básica no Rio Grande do Sul. São Paulo: Fundacentro.

Escalona, E., Sánchez, T., \& Medina, M. G. (2007). Estrategias participativas em laidentificación de la carga de trabajo y problemas de salud em docentes de escuelas primarias. Salud de losTrabajadores, 15(1), 17-35.

Ferreira, M. C., \& Assmar, E. M. L. (2008) Fontes ambientais de estresse ocupacional e burnout: tendências tradicionais e recentes e de investigação. Em: A. Tamayo. (Org.), Estresse e Cultura Organizacional (pp. 21 - 75). São Paulo: Casa do Psicólogo.

Figueiredo, M. F. C. M., Pereira, A. M. S., \& Brás, M. L. M. (2007). Estudo exploratório sobre saúde mental dos professores (Dissertação de Mestrado) Universidade de Aveiro, Aveiro, Portugal.

Galicia, F. A., \& Zermeño M. E. G. (2009). Estrés, agotamientoprofesional (burnout) y saludenprofesores de acuerdo a su tipo de contrato. Ciencia \& Trabajo, 12(33), 172-176.

Gil-Monte, P. R. (2005). El sindrome de quemarse por eltrabajo (burnout). Una enfermidad laboral enlasociedaddelbienestar. Madrid: Pirâmide.

Gil-Monte, P. R., Carlotto M. S., \& Câmara, S. (2010). Validation of the Brazilian version of the "Spanish Burnout Inventory" in teachers. Revista de Saúde Pública, 44(1), 140-147.

Gomes A. A., Silva, G. R., \& Silva, D. V. (2010). A indisciplina numa escola portuguesa: olhares da comunidade educativa. Educação em Revista, 11(1), 93-104.

Gomes, A. R., Oliveira, S., Esteve, A., \& Alvelos, M. (2013). Stress, avaliação cognitiva e burnout: um estudo com professores do ensino superior. Revista Sul Americana de Psicologia, 1(1), 1-20.
Gomes, R. A., Montenegro, N., Peixoto, A. M. B. C., \& Peixoto, A. R. B. C. (2010). Stresse ocupacional no ensino: um estudo com professores do $3^{\circ}$ ciclo e ensino secundário. Psicologia \& Sociedade, 22(3), 587-597.

Jiménez, A. E., Figueroa, M. J., Gutiérrez, J., \& Celis, E. R. M. (2012). Burnout, apoyo social y satisfacciónlaboral en docentes. Revista Semestral da Associação Brasileira de Psicologia Escolar e Educacional, 16(1), 125-134.

Lima, P. G., Barreto, E. M. G., \& Lima, R. R. (2007). Formação docente: uma reflexão necessária. Revista de Educaşão Educereet Educare, 2(4), 91-101.

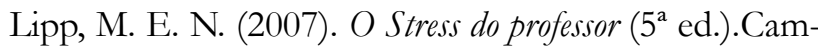
pinas: Papirus. (Original publicado em 2002).

Machado, P. G. B., Porto-Martins, P. C., \& Amorim, C. (2012). Engagement no trabalho entre profissionais da educação. Revista Intersaberes, 7(13), 193-214.

Marqueze, E. C., \& Moreno, R. C. (2009). Satisfação no trabalho e capacidade para o trabalho entre docentes universitários. Psicologia em Estudo, 14(1), 1413-7372.

Maslach, C., \& Leiter, M. P. (1997). The truth about burnout: how organization cause, personal stress and what to do about it. San Francisco: Jossey-Bass.

Maslach, C. \& Leiter, M. P. (1999). Trabalho: fonte de prazer ou desgaste? Guia para vencer o estresse na empresa. Campinas: Papirus.

Monteiro, J. K., Dalagasperina, P., \& Quadros, M. O. (2012). Professores no limite: o estresse no trabalho do ensino privado do Rio Grande do Sul. Porto Alegre: FeteeSul.

Moreira, H. R., Farias, G. O., Bhot, J., \& Nascimento, J. V. (2009). Qualidade de vida no trabalho e síndrome de burnout em professores de educação física do estado de Rio Grande do Sul, Brasil. Revista Brasileira de Atividade Física \& Saúde, 14(2), 115-122.

Navarro, M. L. A., Mas, M. B., \& Jimenez, A. M. L. (2010). Working conditions, burnout and stress symptoms in university professors: validating a structural model of the mediating effect of perceived personal competence. The Spanish Journal of Psychology, 13(1), 284-296.

Noronha, M. M. B, Assunção, A. A., \& D. A. Oliveira. (2008). O sofrimento no trabalho docente: o caso 
das professoras da rede pública de Montes Claros, Minas Gerais. Revista Trabalho, Educação e Saúde, 6(1), 55-85.

Odelius, C. C., \& Codo, W. (1999). Salário. Em W. Codo (Org.), Educação: carinho e trabalho: burnout, a sindrome da desistência do educador, que pode levar à falência da educação (pp.193-203). Petrópolis: Vozes.

Oliveira, D. A. (2003). As reformas educacionais e suas repercussões sobre o trabalho docente. Em D. A. Oliveira, Reformas educacionais na América Latina e os trabalhadores docentes (pp. 13-35). Belo Horizonte: Autêntica.

Ramos, A. R., \& Machado, T. S. (2010). Indisciplina escolar perspectivada por um grupo de alunos do terceiro ciclo de duas escolas de Viana do Castelo. (Dissertação de Mestrado), Universidade de Coimbra, Portugal.

Rocha, V. M., \& Fernandes, M. H. (2008). Qualidade de vida de professores do ensino fundamental: uma perspectiva para a promoção da saúde do trabalhador. Jornal Brasileiro de Psiquiatria, 57(1), 23-27.

Rodrigues, C. D., Chaves, L. B., \& Carlotto, M.S. (2010). Síndrome de burnout em professores de educação pré-escolar. Interação em Psicologia, 14(2), 197-204.

Rojas, S. U. (2010). Estudio de prevalencia del síndrome de quermarse por el trabajo (SQT) y su asociación com sobrecarga y autoeficacia em maestros de primaria de la ciudad de méxico. Ciencia \& Trabajo, 12(35), 257-262.

Rojas, S. U., Ocaña, J. I. S., \& Gil-Monte, R. (2008). Prevalencia del síndrome de quemarse por el trabajo (SQT) (burnout) en maestros mexicanos. Informació Psicologica, 91, 53-63.

Rosso, A. (2011). As representações sociais das condições de trabalho que causam desgaste aos professores estaduais paranaenses. Educação Temática Digital, 13(1), 269-275.

Santos, A. A., \& Sobrinho, C. L. N. (2011). Revisão sistemática da prevalência de burnout em professores do ensino fundamental e médio. Revista Baiana de Saúde Pública, 35(2), 299-319.

Santos, G. E. O. (s/a). Cálculo amostral: calculadora online. Disponível em http://www.calculoamostral.vai.la.

Schwarzer, R., \& Hallum, S. (2008). Perceived teacher self-efficacy as a predictor of job stress and burnout: mediation analyses. Journal Compilation: International Association of Applied, 57, 152-171.

Servilha, E. A. M., \& Arbach, M. P. (2011). Queixas de saúde em professores universitários e sua relação com fatores de risco presentes na organização do trabalho. Distúrb Comum, 23(2), 181-19.

Silvério, M. R., Patrício, Z. M., Bordbeck, I. M., \& Grosseman, S. (2010). O Ensino na área da saúde e sua repercussão na qualidade de vida docente. Revista Brasileira de Educação Médica, 34 (1), 65-73.

Tamayo, M. R., \& Tróccoli, B. T. (2002). Burnout no trabalho. Em A. M. Mendes, L. O. Borges, \& M. C. Ferreira, Trabalho em transição, saúde em Risco (pp. 4364). Brasília: UNB.

Trigo, T. R., Teng, C. T., \& Hallak, J. E. C. (2007). Síndrome de burnout ou estafa profissional e os transtornos psiquiátricos. Revista Psiquiátrica Clínica, 34(5), 223-233.

Xavier, E. P. (1978). Comportamento organizacional, Psicologia Aplicada a Administração. Porto Alegre: Bureau.

Recebido em: 07/06/2013

Reformulado em: 02/12/2013

Segunda reformulação em: 11/02/2014

Aprovado em: 19/04/2014 
Sobre as autoras:

Patrícia Dalagasperina é psicóloga pela Universidade Regional Integrada do Alto Uruguai e das Missões, mestre e doutoranda em Psicologia Clínica pela Universidade do Vale do Rio dos Sinos.

Janine Kieling Monteiro é psicóloga, mestre e doutora em Psicologia pela Universidade Federal do Rio Grande do Sul e atua como professora do Programa de Pós-Graduação em Psicologia da Universidade do Vale do Rio dos Sinos.

Contato com as autoras:

Universidade do Vale do Rio dos Sinos (UNISINOS)

Departamento de Pós-Graduação em Psicologia Clínica - Centro de Ciências da Saúde Avenida UNISINOS, $n^{\circ} 950$ - Bairro Cristo Rei.

CEP: 93.022-000 - São Leopoldo/RS

E-mail: patricia.mspsi@gmail.com 
